\title{
Antimicrobial Sensitivity Pattern in Surgical PatientsAdmitted to Intensive Care Unit, Northwest Region, Kingdom of Saudi Arabia
}

\author{
Ibrahim Albalawi \\ Associate Professor of Department of Surgery, Faculty of Medicine, University of Tabuk, \\ P.O.Box:4333-Tabuk 71491 Kingdom of Saudi Arabia
}

\begin{abstract}
Antimicrobial resistance is challenging for the health care professionals especially in intensive care unit. Most of the hospitals in developing countries yet to understand this phenomenon in order to succeed in antimicrobial therapy among the critically ill patients. The present study aimed to investigate the commonly available bacteria in ICU and antimicrobial sensitivity pattern of those bacteria in King Khalid Hospital, Tabuk, Kingdom of Saudi Arabia. The study has recruited 85 surgical patients admitted to intensive care unit (ICU) and bacterial isolation was carried out from their blood samples. Over all, gram negative bacteria is most common isolated in the study site (54\%). However, $42 \%$ staphylococcus was isolated from the blood culture of the study population. Gram negative bacteria divided into two categories as enterobacteriaceae species and nonenterobacteriaceaespecies. Staphylococcus species is the most common isolated bacteria found to have higher sensitive to ceftriaxone, aztreonam, amoxicillin-clavulanic acid, colisitin, amikacin, cefepime, nitrofurantoin;however, high resistance was evident tocarbapenemantimicrobials (meropenem, ertapenem, imipenem) and fluroquinolones.Acinetobacter second common isolated bacteria only sensitive to colistin and sulphamethoxazole + trimethoprim antimicrobials. Antimicrobials sensitivity pattern highly differs between enterobacteriaceae and non-enterobacteriaceae bacteria's. Hence, the careful selection of antimicrobials is recommended in order to succeed in antimicrobial therapy.
\end{abstract}

Keywords: Antimicrobials, sensitivity, resistance.

\section{INTRODUCTION}

Antimicrobials resistance is a major worldwide problem especially in the intensive care unit (ICU), including in Saudi Arabia. It has been realized that the spread of drug-resistant organisms in the ICU is treated to the widespread use of antimicrobials. The rate of antimicrobial resistance in the ICU is several folds higher than the general hospital setting. Many surveillance efforts have drawn attention to this phenomenon [1-4].

Worldwide, ICUs are faced with increasingly rapid emergence and spread of AM-resistantbacteria because of frequent use of broad spectrum AMs, crowding of patients with high levels of disease acuity in relatively small, specialized areas of the hospital, shortage ofnursing and other supporting staff due to economic pressures (which increases thelikelihood of person-to-person transmission of microorganisms) and the presence of morechronicallyand acutely ill patients who require prolonged hospitalization $[5,6]$.

Healthcare Associated Infections (HAIs) are an important health problem in terms of morbidities, mortalities and economic consequences, worldwide. The most important risk factors for ICU-acquired infections in our study were an ICU stay of more than 7 days, respiratory failure, sedative medication and operation (before or after admission to ICUs). The patients with respiratory failure were the most at risk for ICU-acquired infections [7].Reports were scarce in regard to antimicrobials sensitivity pattern in ICU in Saudi Arabia especially in Northern Province. Therefore, this study aimed to assess the prevalence of bacteria-causing infections in patients in ICU, as well as their antimicrobial resistant patterns in Northern Province, Tabuk, Kingdom of Saudi Arabia.

\section{METHODS}

A retrospective study conducted at King Khalid Hospital in Tabuk, Kingdom of Saudi Arabia during the period from January to December 2014, following the ethical guidelines for patient data privacy eighty-five blood cultures of adult surgical patients ( $>18$ years old) admitted to the ICU were reviewed. The research was approved by the ethical committee of the King Khalid Hospital, Tabuk, Kingdom of Saudi Arabia.

Data pertaining to all microbial isolates and their antimicrobials susceptibility data were retrospectively collected and entered into the Microsoft Excel Database. The data were analyzed separately for the predominant Gram-negative isolates including enterobacteriaceae(Escherichia coli [E. coli], serratiaspecies( spp),enterobacterspp, salmonella spp, proteusspp.P. aeroginosa,Acinetobacterspp) andother nonenterobacteriaceae gram-negative bacteria (Acinetobacterspp, klebsiellaspp, pseudomonas 
spp,achromobacterspp.) and gram positive isolates (Staphylococcus spp and enterococcus spp).

Bacterial isolation according to morphology followed according to Benson et al., 1994. Antimicrobials sensitivity was ascertained using the standard disc diffusion method according to the National Committee for Clinical Laboratory Standard (NCCLS, 2000). The Vitex 12, Phoenix, and Micro scans were used [8].

\section{RESULTS}

Out of 85 isolated blood culture samples at the intensive care unit, King Khalid Hospital, Tabuk, KSA January to December 2014, represents equal gender distribution (Male 43; Female 42). Gram-negative bacteria's commonly present among the isolated samples $(n=46)$ followed by gram-positive bacteria's $(n=39)$. Among the Gram-negative bacteria's, we observed the equal distribution of enterobacteriaceae $(n=23)$ and other than enterobacteriaceae (non-enterobacteriaceae) $s p p(\mathrm{n}=23)$. Enterobacteriaceaespp including E.coli (8), serratia (6), enterobacter (6), salmonella (2) and proteus (1) spp were observed in the isolated blood culture. Acientobacter (12), klebsiella (7), pseudomonas (2), achromobacter (2) were the non-enterobacteriaceaespp observed among the culture. Gram -positive bacteria's including staphylococcus spp $(\mathrm{n}=36)$ and enterococcusspp $(\mathrm{n}=3)$ also found in isolated blood culture. (Table 1).Sensitivity pattern of antimicrobials was studied among the above said isolated cultures. Ceftriaxone, aztreonam, amoxicillin-clavulanic acid, colisitin, amikacin, cefepime, nitrofurantoin were found to have highly sensitive and the remaining antimicrobialss found to have highly resistant to staphylococcus spp. However, Penicillin antimicrobialss (Ampicillin, amoxicillinclavulanic acid and piperacillin-tazobactum) found to have sensitive and the remaining antimicrobialss found to have resistant to enterococcus spp. (Table 2)

Table 3 reveals the sensitivity pattern of gram negative enterobacteriaceaespp shows that carbapenemantimicrobialss (Ertapenem, imipenem, meropenem) shows high sensitivity and remaining antimicrobialss shows moderate-to-high resistant to all enterbacteriaceaespp. Gentamycin and ceftazidime sensitive to E.coli, serratia, enterobacter and salmonella spp; however, cefoxitin, ceftriaxone, cefepime and amoxicillin-clavulanic acid were sensitive to proteusspp.

The present study was attempted to investigate the sensitivity pattern on non-enterobacteriaceaespp reveals that colistin and septrin were found to have sensitive to Acientobacter, pseudomonas and achromobacterspp; however, aminoglycosides and carbapenemantimicrobialss found to have greater sensitivity to klebsiellaspp. Cephalosporins, fluroquinolones and pencillin antimicrobials show high resistant to non-enterobacteriaceaespp. (Table 4)

\section{DISCUSSION}

$54 \%$ of isolated culture formed Gram-negative bacteria in the present study and this finding is substantiated by the various ICU studies reports published previously $[9,10,11,12]$. Gender was not a risk factor for infection and mortality in the present study, as it was in other studies [12-13].The most common isolate among the blood culture is staphylococci spp, which is approximately $42 \%$ of isolates. The result coincides with previous results of Fridkin et al [14] and Nermin KS et al (10). Ceftriaxone, aztreonam, amoxicillin-clavulanic acid, colisitin, amikacin, cefepime, nitrofurantoin were found to have high sensitivity; however, highresistance is observed with carbapenemantimicrobialss and fluroquinolones $(50 \%)$ which are consistent with the previous report having 68\% from Saudi Arabia [15].

Non-enterobacteriaceae bacteria's including Acientobacter, klebsiella, pseudomonas, achromobacter found to have higher resistant to all antimicrobialss and this is also consistent with the previous report which indicates a very high rate of multidrug resistance (MDR) in Saudi Arabia [15] and the study carried out inthe USA between 1993 to 2004 [16]. It is emphasized that the increased incidence of MDR among ICU patients may be due to reasons, such as prior antimicrobial use, inadequate antimicrobial therapy, and long antimicrobial exposures that exert antimicrobial pressures that lead to the emergence of resistance in a previously susceptible GN bacterium [15]. Interestingly, colistin and sulphamethoxazole + trimethoprim are found to have moderate to high sensitivity to above said non-enterobacteriaceaegram negative bacteria's. Therefore, the emphasized the physicians to manage the gram negative infection with colistin and sulphamethoxazole + trimethoprim like drugs which also known cost effective.

Comparison of the sensitivity pattern for $E$. coli in our study shows carbapenemantimicrobialss (Ertapenem, imipenem, meropenem), amikacin, gentamicin, ceftazidimeand amoxicillin-clavulanic acid found to have higher sensitivity and the remaining antimicrobialss had moderate sensitivity in the present study. On the other hand, colistin is the only antimicrobials shows $100 \%$ resistance to E.coli, which is consistent with the result of the previous study [17]. Enterobacter is sensitive to carbapenemantimicrobialss (Ertapenem, imipenem, meropenem), amikacin, gentamicin, ceftazidime, piperacillin-tazobactum, septrin, nitrofurantoin, ciprofloxacin etc. Serratia is highly sensitive to most of the antimicrobialss except cephalothin, cefuroxime, cefoxitin, ampicillin, amoxicillin-clavulanic acid, colistin. Nitrofurantoin etc. On the contrary, serratia has $100 \%$ sensitivity to ceftriaxone in our study and resistance has reported in the previous study [18]. 
We present this data as an observation of the trends in antimicrobial susceptibility patterns over twelve months period in the ICU of our study site. We hope that this data will be useful to healthcare professionals in order to decide and/or update the antimicrobials policy in the concerned hospital and region. We believe the continuous surveillance is needed to achieve successful antimicrobial therapy in ICU.

\section{LIMITATIONS OF THE STUDY}

Antimicrobials disc sensitivity test results may vary withthe hospital setting, while infection rate in a hospital may depend on the hospital environment, antimicrobials use and other infection control practices. All these would limit the applicability of the findings of this study to other hospital settings.

\section{CONCLUSION}

Staphylococcus spp is the commonly isolated bacteria found to have higher resistance to carbapenemantimicrobialss (meropenem, ertapenem, imipenem) and fluroquinolones.Acinetobacter second common isolated bacteria only sensitive to colistin and sulphamethoxazole + trimethoprim antimicrobials. Antimicrobials sensitivity pattern highly differs between enterobacteriaceae and non-enterobacteriaceae bacteria's. Hence, the careful selection of antimicrobials is recommended in order to succeed in antimicrobial therapy.

\section{REFERENCES}

[1] Jones MDE, Draghi DC, Thrornsberry C, Karlowsky JA, Sahm DF, Wenzel RP. Emerging resistance among bacterial pathogens in the intensive care unit - a European and North American surveillance study (2000 - 2002). Ann ClinMicrobiolAntimicrob 2004;3:14.

[2] BronzwaerSl, Cars O, Buchholz U, Molstad S, Goettsch W, Veldhuijzen IK. A European study on the relationship between antimicrobial use and antimicrobial resistance. Emer Infect Dis 2002;8:278:278282.

[3] Hadi U, Duerink DO, Lestari ES, Nagelkerke NJ, Keuter M, Huis Veld D. Audit of antimicrobials prescribing in two governmental teaching hospitals in Indonesia. Clin microbial Infect 2008;14:698-707.

[4] Vincent JL, Rello J, Marshall J, Silva E, Anzueto A, Martin CD. International study of the prevalence and outcomes of infection in intensive care units. JAMA 2009;302(21):2323-2329.

[5] Kollef MH, Fraser VJ. Antimicrobials resistance in intensive care unit setting. Ann Intern Med 2001; 134: 298-314.

[6] Shankar PR, Partha P, Dubey AK, Mishra P, Deshpande VY. Intensive care unit drug utilization in a teaching hospital in Nepal. Kathmandu Univ Med J 2005; 3: 130-137.

[7] Meric M, Willke A, Caglayan C, Toker K (2005). Intensive care unitacquired infections: incidence, risk factors and associated mortality in a Turkish university hospital. Jpn. J. Infect. Dis. 58: 297-302.

[8] Alfred EB. Benson's Microbiological Applications (complete version) A Laboratory Manual in General Microbiology. 3rd edition.McGraw-Hill, 2011.

[9] Vincent, J. L., Bihari, D. J., Suter, P. M., Bruining, H. A., White, J., Nicolas-Chanoin, M. H., Wolff, M., Spencer, C. and Hemmer, M. (1995): The prevalence of nosocomial infection in intensive care units in Europe. Result of the European Prevalence of Infection in Inten-sive Care (EPIC) study. JAMA, 274, 639-644.

[10] Richards, M. J., Edwards, J. R., Culver, D. H. and Gaynes, R. P. (2000): Nosocomial infections in combined medical-sugical intensive care units in the United States. Infect. Control Hosp. Epidemiol., 21, 510-515.

[11] National Nosocomial Infections Surveillance (NNIS) System Report (1999): Data summary from January 1990-May 1999. Am. J. Infect. Control., 27, 520-532.

[12] de Leon-Rosales, S. P., Molinar-Ramos, F., Dominguez-Cherit, G., Rangel-Frausto, M. S. and VazquezRamos, G. (2000): Prevalence of infections in intensive care units in Mexico: A multicenter study. Crit. Care Med., 28, 1316-1321

[13] Appelgren, P., Hellstrom, I., Weitzberg, E., Soderlund, V., Bindsley, L. and Ransjo, U. (2001): Risk factors for nosocomial intensive care infection: a long-term prospec-tive analysis. ActaAnesthesiol. Scand., 45, 710-719.

[14] Fridkin SK, Edwards JR, Tenover FC, Gaynes RP, McGowan JE Jr. Antimicrobial resistance prevalence rates in hospital antibiograms reflect prevalence rates among pathogens associated with hospital-acquired infections. Clin Infect Dis 2001; 33: 324-330.

[15] Nermin K, Abdulmageed M, Noura A. Antimicrobial-resistant bacteria in a general intensive care unit in Saudi Arabia. Saudi Med J 2010; 31 (12):1341-1349. 
[16] Lockhart SR, Abramson MA, Beekman SE, Gallagher G, Riedel SR, Diekema DJ, et al. Antimicrobial resistance among Gram-negative bacilli as causes of infections in intensive care unit patients in the United States between 1993 and 2004. J ClinMicrobiol2007; 45: 3352-3359.

[17] Kaushal V Sheth, Tejas K Patel, Saklainhaider S Malek, CB Tripathi. Antimicrobials Sensitivity Pattern of Bacterial Isolates from the Intensive Care Unit of a Tertiary Care Hospital in India. Tropical Journal of Pharmaceutical Research December 2012; 11 (6): 991-999.

[18] MaksimRadji, SitiFauziah, NurganiAribinuk. Antimicrobials sensitivity pattern of bacterial pathogens in the intensive care unit of Fatmawati Hospital, Indonesia. Asian Pacific Journal of Tropical Biomedicine 2011:39-42.

Table 1 Distribution of gram-positive and gram-negative bacteria's among the isolated blood culture

\begin{tabular}{|c|c|}
\hline Bacteria type & No. of isolated blood culture \\
\hline \multicolumn{2}{|l|}{ Gram Positive } \\
\hline Staphyloccus & 36 \\
\hline Enterococuus & 3 \\
\hline \multicolumn{2}{|l|}{ Gram Negative } \\
\hline \multicolumn{2}{|l|}{ Enterobatericea } \\
\hline E.Coli & 8 \\
\hline Enterobacter & 6 \\
\hline Serratia & 6 \\
\hline Salmonella & 2 \\
\hline Proteus & 1 \\
\hline \multicolumn{2}{|l|}{ Non-Enterobatericea } \\
\hline Acinobacter & 12 \\
\hline Klebsiella & 7 \\
\hline Pseudomonas & 2 \\
\hline Acromobacter & 2 \\
\hline
\end{tabular}

Table 2 Antibiotic sensitivity pattern of gram-positive spp

\begin{tabular}{|l|c|c|c|c|c|c|}
\hline \multirow{2}{*}{\multicolumn{1}{|c|}{ Antibiotic }} & \multicolumn{3}{c|}{ Staphyloccus } & \multicolumn{3}{c|}{ Enterococuus } \\
\cline { 2 - 7 } & S & I & R & S & I & R \\
\hline Amikacin & 27 & 3 & 6 & 0 & 0 & 3 \\
\hline Gentamicin & 1 & 32 & 3 & 0 & 0 & 3 \\
\hline Ertapenem & 8 & 27 & 1 & 0 & 0 & 3 \\
\hline Imepenem & 13 & 20 & 3 & 0 & 0 & 3 \\
\hline Meropenem & 17 & 1 & 18 & 0 & 1 & 2 \\
\hline Cephalothin & 16 & 13 & 7 & 0 & 2 & 1 \\
\hline Cefuroxime & 12 & 20 & 4 & 0 & 2 & 1 \\
\hline Cefoxitin & 11 & 24 & 1 & 0 & 3 & 0 \\
\hline Ceftazidime & 15 & 16 & 5 & 1 & 2 & 0 \\
\hline Ceftriaxone & 29 & 2 & 5 & 1 & 0 & 2 \\
\hline Cefepime & 27 & 2 & 7 & 1 & 2 & 0 \\
\hline Aztreonam & 29 & 3 & 4 & 0 & 3 & 0 \\
\hline Ampicillin & 17 & 16 & 3 & 3 & 0 & 0 \\
\hline Amoxicillin-clavulanic acid & 29 & 4 & 3 & 2 & 0 & 1 \\
\hline Piperacillin-tazobactum & 20 & 12 & 4 & 2 & 1 & 0 \\
\hline Colistin & 28 & 0 & 8 & 0 & 2 & 1 \\
\hline Septrin & 10 & 19 & 7 & 1 & 0 & 2 \\
\hline Nitrofurantoin & 27 & 0 & 9 & 0 & 0 & 3 \\
\hline Ciprofloxacin & 5 & 5 & 26 & 1 & 0 & 2 \\
\hline Levofloxacin & 22 & 12 & 2 & 0 & 3 & 0 \\
\hline
\end{tabular}

S- Sensitive; I - Intermediate resistant; R- Resistant. 
Table 3 Antibiotic sensitivity pattern of gram-negative enterobacteriaceaespp

\begin{tabular}{|l|c|c|c|c|c|c|c|c|c|c|c|c|c|c|c|}
\hline \multirow{2}{*}{ Antibiotic } & \multicolumn{3}{|c|}{ E.Coli } & \multicolumn{3}{|c|}{ Serratia } & \multicolumn{1}{c|}{ Enterobacter } & \multicolumn{3}{|c|}{ Salmonella } & \multicolumn{3}{|c|}{ Proteus } \\
\cline { 2 - 14 } & S & I & R & S & I & R & S & I & R & S & I & R & S & I & $\mathbf{R}$ \\
\hline Amikacin & 6 & 1 & 1 & 6 & 0 & 0 & 6 & 0 & 0 & 0 & 1 & 1 & 0 & 1 & 0 \\
\hline Gentamicin & 6 & 1 & 1 & 6 & 0 & 0 & 6 & 0 & 0 & 1 & 1 & 0 & 0 & 1 & 0 \\
\hline Ertapenem & 4 & 3 & 1 & 6 & 0 & 0 & 6 & 0 & 0 & 2 & 0 & 0 & 1 & 0 & 0 \\
\hline Imepenem & 7 & 0 & 1 & 6 & 0 & 0 & 6 & 0 & 0 & 2 & 0 & 0 & 1 & 0 & 0 \\
\hline Meropenem & 7 & 1 & 0 & 6 & 0 & 0 & 6 & 0 & 0 & 2 & 0 & 0 & 1 & 0 & 0 \\
\hline Cephalothin & 2 & 5 & 1 & 0 & 6 & 0 & 0 & 0 & 6 & 1 & 0 & 0 & 0 & 1 & 0 \\
\hline Cefuroxime & 3 & 5 & 0 & 0 & 6 & 0 & 0 & 0 & 6 & 1 & 0 & 0 & 0 & 1 & 0 \\
\hline Cefoxitin & 6 & 1 & 1 & 0 & 6 & 0 & 0 & 0 & 6 & 2 & 0 & 0 & 1 & 0 & 0 \\
\hline Ceftazidime & 7 & 1 & 0 & 6 & 0 & 0 & 6 & 0 & 0 & 2 & 0 & 0 & 0 & 0 & 1 \\
\hline Ceftriaxone & 3 & 4 & 1 & 6 & 0 & 0 & 0 & 0 & 6 & 2 & 0 & 0 & 1 & 0 & 0 \\
\hline Cefepime & 4 & 4 & 0 & 6 & 0 & 0 & 6 & 0 & 0 & 2 & 0 & 0 & 1 & 0 & 0 \\
\hline Aztreonam & 4 & 3 & 1 & 6 & 0 & 0 & 0 & 0 & 6 & 2 & 0 & 0 & 0 & 1 & 0 \\
\hline Ampicillin & 3 & 4 & 1 & 0 & 6 & 0 & 0 & 2 & 4 & 2 & 0 & 0 & 0 & 1 & 0 \\
\hline Amoxicillin-clavulanic acid & 7 & 0 & 1 & 0 & 6 & 0 & 0 & 6 & 0 & 1 & 0 & 1 & 1 & 0 & 0 \\
\hline Piperacillin-tazobactum & 6 & 0 & 2 & 6 & 0 & 0 & 4 & 2 & 0 & 0 & 1 & 1 & 0 & 1 & 0 \\
\hline Colistin & 0 & 2 & 6 & 0 & 6 & 0 & 0 & 0 & 6 & 1 & 0 & 1 & 0 & 1 & 0 \\
\hline Septrin & 3 & 4 & 1 & 6 & 0 & 0 & 6 & 0 & 0 & 1 & 0 & 1 & 0 & 1 & 0 \\
\hline Nitrofurantoin & 4 & 2 & 2 & 0 & 6 & 0 & 4 & 0 & 2 & 0 & 1 & 0 & 0 & 1 & 0 \\
\hline Ciprofloxacin & 3 & 4 & 1 & 6 & 0 & 0 & 6 & 0 & 0 & 0 & 1 & 0 & 0 & 0 & 1 \\
\hline Levofloxacin & 4 & 2 & 2 & 6 & 0 & 0 & 0 & 0 & 6 & 0 & 1 & 0 & 0 & 1 & 0 \\
\hline
\end{tabular}

S- Sensitive; I - Intermediate resistant; R- Resistant.

Table 4 Antibiotic sensitivity pattern of gram-negative non-enterobacteriaceaespp

\begin{tabular}{|l|c|c|c|c|c|c|c|c|c|c|c|c|}
\hline \multirow{2}{*}{ Antibiotic } & \multicolumn{3}{|c|}{ Acinetobacter } & \multicolumn{3}{c|}{ Klebsiella } & \multicolumn{3}{c|}{ Pseudomonas } & \multicolumn{3}{c|}{ Acromobacter } \\
\cline { 2 - 14 } & S & I & R & S & I & R & S & I & R & S & I & R \\
\hline Amikacin & 0 & 10 & 2 & 7 & 0 & 0 & 2 & 0 & 0 & 0 & 0 & 2 \\
\hline Gentamicin & 2 & 9 & 1 & 3 & 4 & 0 & 1 & 0 & 1 & 0 & 2 & 0 \\
\hline Ertapenem & 0 & 7 & 5 & 7 & 0 & 0 & 0 & 0 & 2 & 0 & 0 & 2 \\
\hline Imepenem & 0 & 1 & 11 & 7 & 0 & 0 & 0 & 1 & 1 & 2 & 0 & 0 \\
\hline Meropenem & 0 & 9 & 3 & 7 & 0 & 0 & 1 & 0 & 0 & 2 & 0 & 0 \\
\hline Cephalothin & 1 & 5 & 6 & 0 & 7 & 0 & 0 & 0 & 2 & 0 & 0 & 2 \\
\hline Cefuroxime & 0 & 5 & 7 & 0 & 7 & 0 & 0 & 0 & 2 & 0 & 0 & 2 \\
\hline Cefoxitin & 1 & 5 & 6 & 4 & 3 & 0 & 1 & 1 & 0 & 0 & 0 & 2 \\
\hline Ceftazidime & 0 & 11 & 1 & 2 & 4 & 1 & 0 & 0 & 2 & 2 & 0 & 0 \\
\hline Ceftriaxone & 0 & 5 & 7 & 1 & 6 & 0 & 1 & 0 & 1 & 0 & 2 & 0 \\
\hline Cefepime & 0 & 10 & 2 & 0 & 5 & 2 & 2 & 0 & 0 & 0 & 2 & 0 \\
\hline Aztreonam & 1 & 5 & 6 & 0 & 5 & 2 & 0 & 2 & 0 & 0 & 2 & 0 \\
\hline Ampicillin & 0 & 11 & 1 & 0 & 7 & 0 & 0 & 1 & 1 & 0 & 0 & 2 \\
\hline Amoxicillin-clavulanic acid & 1 & 10 & 1 & 1 & 5 & 0 & 1 & 0 & 1 & 0 & 2 & 0 \\
\hline Piperacillin-tazobactum & 1 & 7 & 4 & 4 & 2 & 1 & 2 & 0 & 0 & 2 & 0 & 0 \\
\hline Colistin & 9 & 1 & 2 & 1 & 0 & 6 & 1 & 1 & 0 & 2 & 0 & 0 \\
\hline Septrin & 9 & 3 & 0 & 1 & 6 & 0 & 1 & 1 & 0 & 2 & 0 & 0 \\
\hline Nitrofurantoin & 1 & 11 & 0 & 1 & 4 & 2 & 2 & 0 & 0 & 0 & 2 & 0 \\
\hline Ciprofloxacin & 0 & 12 & 0 & 1 & 4 & 2 & 1 & 0 & 1 & 0 & 2 & 0 \\
\hline Levofloxacin & 0 & 4 & 8 & 2 & 5 & 0 & 0 & 0 & 2 & 0 & 0 & 2 \\
\hline
\end{tabular}

S- Sensitive; I - Intermediate resistant; R- Resistant. 